\title{
Kemampuan Biofilter Anaerob Berdasarkan Jenis Media dalam Pengolahan Air Limbah Domestik Tahun 2016
}

\author{
Donal Nababan ${ }^{\mathrm{a}}$, Mido Ester Juniati Sitorus ${ }^{\mathrm{b} *}$, Ivan Elisabeth Purba ${ }^{\mathrm{c}}$, Netti Etalia Br. Brahmana ${ }^{\mathrm{d}}$, \\ Evawani Martalena Silitonga ${ }^{\mathrm{e}}$ \\ Universitas Sari Mutiara Indonesia, Medan 20124, Indonesia \\ anababan_donal@yahoo.com; b mido71torus@yahoo.com*; cpoerba.ivanelis@gmail.com, dbrahmananetti@gmail.com, eevawani.martalena@gmail.com \\ *corresponding author
}

ARTICLE INFO

Keywords

Domestic wastewater

Anaerobic biofilter

By type of media

\begin{abstract}
Domestic wastewater is used water that cannot be used anymore for its original use, either containing human waste (feces) or from kitchen, bathroom and washing activities. The more dense the population in a settlement the more waste must be controlled. One simple way to treat domestic wastewater is to use anaerobic biofilter based on the type of media. The media used were broken stones, plastic sheets, and coconut shell charcoal. The purpose of this study was to determine the ability of anaerobic biofilter based on the type of media in domestic wastewater treatment. The parameters measured are BOD, COD and $\mathrm{PH}$. Anaerobic biofilter performance is determined by looking at the difference in levels before and after using the media. This research is a quasi-experimental research with one group pretest-posttest design. The sample of this study were 10 samples taken from repetition 3 times in one experiment, the process was done by a batch system. The results showed an average reduction in BOD on plastic sheet media by $84.76 \%$, COD by $84.77 \%$, PH by $32.3 \%$. The average reduction in BOD in the stone medium was $80.57 \%$, COD was $80.59 \%$, PH was $29.66 \%$. The average reduction in BOD in coconut shell charcoal media was $69.72 \%$, COD was $77.84 \%$, PH was $24 \%$.
\end{abstract}

\section{Pendahuluan}

Air adalah zat yang sangat penting bagi kehidupan semua makhluk yang berada di bumi. Tidak hanya penting bagi manusia, air merupakan penting bagi makhluk hidup baik hewan maupun tumbuhan. Sekitar $71 \%$ bumi mengandung air dan volume air dalam tubuh manusia ratarata $65 \%$ dari total beratnya, dan volume tersebut sangat bervariasi pada masing- masing orang, bahkan bervariasi antar bagian- bagian tubuh tersebut. Beberapa organ tubuh manusia yang mengandung banyak air, antara lain, otak $74,5 \%$, tulang $22 \%$, ginjal $82 \%$, otot $75,6 \%$ dan darah $83 \%$. Ditinjau dari sudut ilmu kesehatan masyarakat, penyediaan sumber air bersih harus dapat memenuhi kebutuhan masyarakat karena persediaan air yang terbatas memudahkan timbulnya penyakit di masyarakat. Volume rata-rata kebutuhan air setiap individu per hari berkisar antara 150-200 liter atau 35-40 galon. Kebutuhan air tersebut bervariasi dan tergantung pada keadaan iklim, standar kehidupan dan kebiasaan masyarakat [1].

Air limbah adalah cairan buangan yang berasal dari rumah tangga, industri dan tempattempat umum lainnya dan biasanya mengandung bahan-bahan atau zat yang dapat membahayakan kehidupan manusia serta mengganggu kelestarian lingkungan. Air limbah rumah tangga sebagian besar mengandung bahan organik sehingga memudahkan di dalam pengolahannya. Sebaliknya, limbah industri lebih sulit pengolahannya karena mengandung pelarut mineral, logam berat, dan zat-zat organik lain yang bersifat toksik [1]. Menurut Kodoatie dan sjarief (2005) dalam skripsi 
Reza Cordova (2008) air limbah domestik merupakan air bekas yang tidak dapat dipergunakan lagi untuk keperluan semula, baik yang mengandung kotoran manusia (tinja) atau dari aktivitas dapur, kamar mandi dan cuci. Dimana kuantitasnya 50-70\% dari rata-rata pemakaian air bersih sekitar 120-140 liter per orang per hari.

Buangan rumah tangga, baik berupa air cucian kamar mandi serta buangan tinja yang dibuang ke badan air akan mempengaruhi kondisi badan air tersebut. Semakin padat penduduk yang berada di suatu permukiman akan semakin banyak limbah yang harus dikendalikan. Volume air limbah rumah tangga bergantung pada volume pemakaian air penduduk setempat. Penggunaan air untuk keperluan sehari-hari mungkin kurang dari 10 liter per orang di daerah yang sumber airnya berasal dari kran umum, sedangkan di daerah yang sumber airnya berasal dari sumur pompa dapat mencapai 200 liter per orang [1].

Berdasarkan hasil survei sementara bahwa masyarakat di sekitar wilayah Medan, Kecamatan Medan Helvetia tepatnya di Jalan Eka Prasetya. Kondisi limbah cair yang ada di daerah tersebut perlu diperhatikan untuk menciptakan kesehatan lingkungan. Segala aktivitas rumah tangga seperti mencuci pakaian, mencuci piring, memasak, mandi, dan bahkan tidak jarang kita juga dapat melihat orang yang sengaja membuang air bekas cucian ikan mentah dan berbagai jenis sampah plastik dibuang dengan sembarangan langsung ke selokan.

Penduduk Eka Prasetya merupakan lingkungan pendidikan yang seharusnya tidak membuang air limbah ke selokan yang airnya tidak mengalir, seharusnya air limbah dibuang ke pembuangan air limbah rumah tangga dan pembuangan sampah rumah tangga dibuang pada tempat sampah, oleh karena itu seharusnya tempat sampah tersedia di lingkungan rumah masing-masing.

Sementara penduduk mayoritas membuang limbahnya dengan sembarangan. Penduduk belum ada yang memiliki instalasi pembuangan air limbah yang baik, sehingga semua dialirkan langsung ke parit. Air limbah rumah tangga pada umumnya memiliki bahan- bahan yang mengandung deterjen, pemutih ataupun zat kimia berbahaya lainnya yang dihasilkan dari perumahan dapat menimbulkan pencemaran [2], bahkan sering menimbulkan bau tidak enak dan juga dapat berdampak buruk untuk air tanah bila penduduk masih ada yang menggunakan air sumur.

Air limbah tersebut harus diolah agar tidak mencemari dan tidak membahayakan kesehatan lingkungan. Proses pengolahan air limbah memiliki beberapa cara, salah satunya dengan proses biologis. Pengolahan biologis terbagi atas proses aerobik dan anaerobik. Anaerobik adalah proses yang memanfaatkan reaksi mikroorganisme untuk mengolah air limbah dalam kondisi tanpa oksigen. Pengolahan air limbah dengan cara anaerobik dalam aplikasinya menggunakan media biofilter dalam reaktor anaerob. Media biofilter yang digunakan bertujuan untuk tempat melekat atau menempelnya mikroorganisme yang terdiri dari bakteri, jamur, ganggang, dan protozoa. Kelebihan biofilter anaerob yaitu lebih efisien, waktu prosesnya lebih cepat. Kelebihan lainnya seperti, derajat stabilitas yang tinggi, produk lumpur buangan biologis rendah, kebutuhan nutrien rendah, dihasilkan gas metan yang dapat digunakan sebagai sumber energi [3]. Tujuan penelitian ini adalah untuk mengetahui penurunan BOD sebelum dan sesudah dilakukan perlakuan dengan media lembaran plastik, media batu pecah, dan media arang tempurung kelapa, mengetahui penurunan COD sebelum dan sesudah dilakukan perlakuan dengan media lembaran plastik, media batu pecah, dan media arang tempurung kelapa, mengetahui penurunan PH sebelum dan sesudah dilakukan perlakuan dengan media lembaran plastik, media batu pecah dan media arang tempurung kelapa.

\section{Metode}

Jenis penelitian ini merupakan eksperimen semu (Quasi Experiment) dengan rancangan one group pretest-postest design dengan pengulangan sebanyak tiga kali. Rancangan tersebut memberi perlakuan terhadap sistem dan kemudian melakukan pengukuran untuk mengetahui apakah perlakuan mengubah nilai pengukuran. Penelitian ini dilaksanakan di Jalan Eka Prasetya Gang Pribadi Kelurahan Helvetia, Kecamatan Medan Helvetia dan di laboratorium. Alasan dipilihnya lokasi penelitian ini adalah selain di daerah tersebut penduduknya yang padat, penggunaan airnya pun terlalu berlebihan pada saat mencuci, memasak dan mandi dan masyarakatnya membuang air bekas aktivitas rumah tangga tersebut langsung ke parit. Waktu pelaksanaan penelitian ini dilakukan mulai bulan Februari-September 2016. 
Objek penelitian ini adalah media biofilter dan air limbah domestik. Untuk air limbah domestik diambil sampel sebanyak 10 kali pengambilan dalam 3 kali pengulangan Penelitian ini prosesnya dengan sistem batch. Air limbah domestik yang ada di bak penampungan, dialirkan semua ke 3 perlakuan secara bersamaan. Alat yang digunakan yaitu: ember plastik sebanyak 10 buah, penggaris, untuk mengukur ketebalan media biofilter saat dimasukkan ke dalam wadah, alat laboratorium, Botol tempat air limbah domestik untuk diperiksa ke laboratorium sebelum dan sesudah melakukan percobaan, Kertas, untuk mencatat hasil laboratorium saat memeriksa air limbah domestik tersebut, pena, untuk menulis hasildari laboratorium saat memeriksa air limbah domestic, termometer suhu, untuk mengukur suhu lingkungan saat melakukan percobaan. Bahan yang digunakan yaitu: air limbah domestik. media biofilter, seperti batu pecahan, plastik yang berasal dari botol-botol minuman air mineral yang dipotong menjadi lembaran dan arang tempurung kelapa.

\section{Hasil dan Diskusi}

\section{Hasil Penelitian}

Suhu Lingkungan dalam Pengembangbiakan Mikroorganisme (Seeding)

Seeding atau disebut juga sebagai pembiakan mikroba merupakan langkah awal dari penelitian reaktor biologis. Dalam tahapan ini dilakukan upaya untuk menumbuhkan mikroorganisme pada media. Mikroorganisme ini sangat berperan penting dalam proses pengolahan biologis ini. Dalam penelitian ini proses seeding yang dilakukan dengan sistem batch yaitu media dan air limbah domestik yang sudah di masukkan ke dalam reaktor, lalu di diamkan selama 12 hari. Hal ini berlangsung sampai didapatkan kondisi pertumbuhan mikroorganisme yang optimum, yaitu menebalnya lendir yang menempel pada media. Pada saat proses seeding, dilakukan pengukuran terhadap suhu lingkungan dan diamati setiap proses seeding berlangsung. Adapun tabel pengukuran suhu dalam proses pembiakan mikroorganisme.

Tabel 1. Suhu Lingkungan dalam Proses Pembiakan Mikroorganisme

\begin{tabular}{ccccc}
\hline $\begin{array}{c}\text { Juli 2016 } \\
\text { Minggu, 31 } \\
\text { Juli 2016 }\end{array}$ & $30^{\circ} \mathrm{C}$ & $35^{\circ} \mathrm{C}$ & $35^{\circ} \mathrm{C}$ & $34^{\circ} \mathrm{C}$ \\
$\begin{array}{l}\text { Senin, 1 } \\
\text { Agustus } \\
\mathbf{2 0 1 6}\end{array}$ & $30^{\circ} \mathrm{C}$ & $33^{\circ} \mathrm{C}$ & $35^{\circ} \mathrm{C}$ & $32^{\circ} \mathrm{C}$ \\
\hline
\end{tabular}

Berdasarkan tabel di atas dapat bahwa suhu lingkungan selama pengembang-biakan mikroorganisme yang diukur pada hari ke pertama sampai hari ke dua belas. Pengukuran dilakukan setiap hari dari pagi, siang, sore dan malam, suhu optimum yaitu $29-35^{\circ} \mathrm{C}$. 
Tabel 2. Hasil Pengamatan Penelitian Selama 12 Hari dalam

\section{Hari ke- $\quad$ Pengamatan}

\begin{tabular}{ll}
\hline Hari ke-1 & Setelah air limbah domestik dimasukan ke masing-masing ember \\
& yang sudah berisi media. Proses pengembang-biakan mikroorganisme \\
& dilakukan dengan proses anaerob yaitu tanpa menggunakan oksigen. \\
& Kemudian ember diberi penutup. Ke-9 ember ditutup sekaligus \\
& dengan penutup yang besar, yang bisa menutupi sampai ke-9 ember. \\
& Dari replikasi pertama sampai replikasi ketiga pada masing-masing \\
& media. Ke-9 ember di letakan dibagian rumah yaitu di dapur.
\end{tabular}

Hari ke- 2 Ke-9 ember di lihat dan diamati apakah tutup mengalami pergeseran atau tidak.

\begin{tabular}{ll}
\hline Hari ke- 3 & $\begin{array}{l}\text { Terlihat ember yang berisi media lembaran plastik pada replikasi } \\
\text { pertama dan replikasi ketiga bergeser dari tutupnya yang } \\
\text { mengakibatkan oksigen masuk pada saat proses pembiakan } \\
\text { mikroorganisme. Namun pada replikasi kedua tidak ada pergeseran. }\end{array}$ \\
\hline Hari ke- 4 & Tetap diamati apakah ke-9 ember mengalami pergeseran atau tidak. \\
\hline Hari ke-5 & $\begin{array}{l}\text { Dilihat pada masing-masingmedia, } \\
\text { mikroorganisme sudah mulai ada }\end{array}$ \\
\hline
\end{tabular}

Tabel 3. Kadar COD Sebelum dan Sesudah Perlakuan dengan Media Lembaran Plastik

\begin{tabular}{cccc}
\hline \multirow{2}{*}{ Replikasi } & \multicolumn{2}{c}{$\begin{array}{c}\text { Media Lembaran } \\
\text { Plastik }\end{array}$} & $\begin{array}{c}\text { Persentase } \\
\text { Penurunan } \\
\text { Kadar (\%) }\end{array}$ \\
& $\begin{array}{c}\text { Sebelum } \\
\text { COD }\end{array}$ & $\begin{array}{c}\text { Sesudah } \\
\text { COD }\end{array}$ & \\
\cline { 2 - 3 } 1 & 410,1 & 74,97 & $81,72 \%$ \\
2 & 410,1 & 46,84 & $88,58 \%$ \\
3 & 410,1 & 65,59 & $84 \%$ \\
Jumlah & 1230,3 & 187,4 & 254,3 \\
Rata-rata & 410,1 & 62,46 & $84,77 \%$ \\
& & & \\
\hline
\end{tabular}

Berdasarkan tabel 3 dapat dilihat kadar COD sebelum dan sesudah perlakuan dengan media lembaran plastik. Kadar COD sebelum perlakuan yaitu 410,1 terjadi penurunan setelah dilakukan perlakuan dengan media lembaran plastik, yaitu pada replikasi pertama 74,97 dengan persentase penurunan sebesar $81,72 \%$, replikasi kedua 46,84 dengan persentase penurunan sebesar $88,58 \%$, replikasi ketiga 65,59 dengan persentase penurunan sebesar $84 \%$. Persentase rata-rata sebesar $84,77 \%$. 
Tabel 4. Kadar PH Sebelum dan Sesudah Perlakuan dengan Media

Lembaran Plastik

\begin{tabular}{cccc}
\hline \multirow{2}{*}{ Replikasi } & \multicolumn{2}{c}{ Media Lembaran } & Persentase \\
& \multicolumn{2}{c}{ Plastik } & Penurunan \\
& Sebelum & Sesudah & Kadar (\%) \\
& PH & PH & \\
\hline 1 & 7,57 & 7,31 & $26 \%$ \\
2 & 7,57 & 7,20 & $37 \%$ \\
3 & 7,57 & 7,23 & $34 \%$ \\
Jumlah & 22,71 & 21,74 & 97 \\
Rata-rata & 7,57 & 7,24 & $32,3 \%$ \\
& & & \\
\hline
\end{tabular}

Berdasarkan tabel 4 dapat dilihat kadar PH sebelum dan sesudah perlakuan dengan media lembaran plastik. Kadar PH sebelum perlakuan yaitu 7,57 terjadi penurunan setelah dilakukan perlakuan dengan media lembaran plastik, yaitu pada replikasi pertama 7,31 dengan persentase penurunan sebesar $26 \%$, replikasi kedua 7,20 dengan persentase penurunan sebesar $37 \%$, replikasi ketiga 7,23 dengan persentase penurunan sebesar $34 \%$, persentase rata-rata sebesar $32,3 \%$.

\section{Pembahasan}

\section{Kadar BOD, COD, PH Sebelum dan Sesudah Perlakuan dengan Media Lembaran Plastik}

Pembiakan mikroba merupakan langkah awal dari penelitian reaktor biologis, dilakukan upaya secara alami untuk mengembangbiakkan mikroorganisme di dalam reaktor yaitu dengan sistem batch, media dan air limbah yang sudah ada direaktor di diamkan beberapa lama sampai mikroorganisme melekat ke media lembaran plastik. Setelah dilakukan proses pengembang biakan bakeri, dengan waktu tinggal selama 12 hari dan dilihat lapisan lendir atau biofilm yang sudah menebal, air limbah tersebut dibuang dan segera diganti dengan air limbah domestik yang baru dengan waktu tinggal selama 4 jam. Kemampuan mikroorganisme pada media lembar plastik dapat dilihat dari persentase penurunan kadar BOD, COD dan PH. Terjadinya penurunan BOD, COD dan PH menunjukkan adanya aktifitas mikroorganisme yang telah menempel semakin banyak dan mendegradasi senyawa organik yang ada di dalam air limbah domestiktersebut.

Hasil pengukuran kadar BOD, COD, PH sebelum dan sesudah pada media lembaran plastik pada tabel 4.3, 4.4 dan 4.5 dapat diketahui bahwa kadar BOD, COD dan PH sebelum perlakuan adalah BOD 131,2 mg/l, COD 410,1 mg/l dan PH 7,57. Kadar BOD sesudah perlakuan menggunakan media lembaran plastik adalah pada replikasi pertama 23,99, replikasi kedua 14,99 dan replikasi ketiga 20,99. Kadar COD sesudah perlakuan dengan media lembaran plastik adalah pada replikasi pertama 74,97, replikasi kedua 46,84 dan replikasi ketiga 65,59. Kadar PH sesudah perlakuan dengan media lembaran plastik adalah pada replikasi pertama 7,31, replikasi kedua 7,20 dan replikasi ketiga 7,23. Penurunan kadar BOD, COD dan PH pada media lembaran plastik menunjukkan bahwa terjadi penguraian zat organik oleh mikrobaanaerob.

Kadar BOD, COD, PH sebelum dan sesudah dengan media lembaran plastik pada replikasi kedua berbeda dengan replikasi pertama dan ketiga yaitu dilihat pada tabel 4.2 pada hari ke-3, di tabel tersebut dijelaskan bahwa terjadi pergeseran pada ember replikasi pertama dan ketiga mengakibatkan oksigen masuk dalam proses pengembangbiakan mikroorganisme, sementara dalam penelitian ini pengolahan air limbah domestik dilakukan dengan proses anaerob yaitu proses degradasi senyawa organik yang terdapat dalam limbah cair oleh bakteri anaerob tanpa kehadiran oksigen (syafila dkk, 2003). Dalam proses tersebut yang sangat berperan adalah aktifitas mikroorganisme dalam mendegradasi senyawaorganik. 
Kemampuan media lembaran plastik sebagai biofilter dikarenakan plastik adalah bahan yang tahan karat, ringan dan memiliki luas permukaan spesifik yang besar dan volume rongga yang besar sehingga dapat melekatkan mikroorganisme dalam jumlah yang besar dengan resiko kebuntuan yang sangat kecil sesuai dengan kriteria pemilihan media menurut jurnal Nusa Idaman Said dan Ruliasih (2005).

Setelah melakukan perlakuan dengan media lembaran plastik dan di lihat hasil sebelum dan sesudah maka dilakukan Uji Wilcoxon untuk melihat perbedaan kadar BOD, $\mathrm{COD}, \mathrm{PH}$ sebelum dan sesudah dilakukan perlakuan dengan media lembaran plastik, hasil yang didapat adalah $p=0.008(p<0.05)$, hal ini menunjukkan adanya perbedaan kadar BOD, COD dan PH sebelum dan sesudah dilakukan perlakuan dengan media lembaran plastik.

\section{Kadar BOD, COD, PH Sebelum dan Sesudah Perlakuan dengan Media Batu Pecah}

Hasil pengukuran kadar BOD, COD, PH sebelum dan sesudah pada media batu pecah pada tabel 4.6, 4.7 dan 4.8 dapat diketahui bahwa kadar BOD, COD dan PH sebelum perlakuan adalah BOD 131,2 mg/l, COD 410,1 mg/l dan PH 7,57. Kadar BOD sesudah perlakuan menggunakan media batu pecah adalah pada replikasi pertama 23,24, replikasi kedua 29,99 dan replikasi ketiga 23,24. Kadar COD sesudah perlakuan dengan media batu pecah adalah pada replikasi pertama 72,63, replikasi kedua 93,72 dan replikasi ketiga 72,63. Kadar PH sesudah perlakuan dengan media batu pecah adalah pada replikasi pertama 7,31, replikasi kedua 7,27 dan replikasi ketiga 7,24.

Kadar BOD, COD, PH sebelum dan sesudah dengan media batu pecah pada replikasi kedua berbeda dengan replikasi pertama dan ketiga. Perbedaan yang terlihat adalah replikasi kedua penurunan lebih sedikit dibanding replikasi pertama dan ketiga yaitu dilihat pada tabel 2 pada hari ke-7, di tabel tersebut dijelaskan bahwa terjadi pergeseran yang cukup jauh dari penutupnya yaitu pada replikasi kedua, mengakibatkan oksigen masuk dalam proses pengembangbiakan mikroorganisme, sementara dalam penelitian ini pengolahan air limbah domestik dilakukan dengan proses anaerob yaitu proses degradasi senyawa organik yang terdapat dalam limbah cair oleh bakteri anaerob tanpa kehadiran oksigen [4]. Dalam proses tersebut yang sangat berperan adalah aktifitas mikroorganisme dalam mendegradasi senyawa organik.

Penurunan kadar BOD, COD dan PH yang terjadi pada media batu pecah menunjukkan adanya aktifitas mikroorganisme yang telah menempel semakin banyak dan mendegradasi senyawa organik yang ada di dalam air limbah domestik tersebut, sama seperti pada media lembaran plastik pembiakan mikroba merupakan langkah awal dari penelitian reaktor biologis, dilakukan upaya secara alami untuk mengembangbiakkan mikroorganisme di dalam reaktor yaitu dengan sistem batch, dengan waktu tinggal selama 12 hari dan diganti dengan air limbah domestik yang baru setelah terjadi penebalan lendir pada media batu pecah lalu didiamkan selama 4 jamjuga.

Kemampuan media biofilter dari bahan anorganik seperti batu pecah, semakin kecil diameternya luas permukaan semakin besar,sehingga jumlah mikroorganisme yang dapat dibiakkan juga semakin besar pula, tetapi volume rongga menjadi lebih kecil [5]. Setelah melakukan perlakuan dengan media batu pecah dan di lihat hasil sebelum dan sesudah maka dilakukan Uji Wilcoxon untuk melihat perbedaan kadar BOD, COD, PH sebelum dan sesudah dilakukan perlakuan dengan media, hasil yang didapat adalah $p=0.008(p<0.05)$, hal ini menunjukkan adanya perbedaan kadar BOD, COD dan $\mathrm{PH}$ sebelum dan sesudah dilakukan perlakuan dengan media batu pecah.

\section{Kadar BOD, COD, PH Sebelum dan Sesudah Perlakuan dengan Media Arang Tempurung Kelapa}

Arang merupakan suatu padatan berpori yang mengandung 85-95\% karbon dan dihasilkan dari bahan yang mengandung karbon dengan pemanasan pada suhu tinggi. Selain dapat digunakan sebagai bahan bakar, arang juga dapat digunakan sebagai adsorben. Daya serap dipengaruhi oleh luas permukaan partikel dan kemampuan ini akan menjadi lebih tinggi bila arang tersebut dilakukan proses aktivasi. Dengan proses aktivasi, arang mengalami perubahan sifat fisika dan kimia. Arang ini disebut arang aktif. 
Arang aktif yang dibuat dengan proses aktivasi memiliki pori-pori yang terbuka sehingga mempunyai daya serap yang besar. Luas permukaan yang tinggi dan struktur pori dari arang aktif merupakan faktor yang perlu dipertimbangkan dalam proses adsorbs ini, arang aktif mempunyai luas permukaan berkisar antara $300-3500 \mathrm{~m}^{2} / \mathrm{gram}$, semakin luas makin baik karena kontak dengan adsorbat semakin besar [6]. Menurut jurnal teknik pomits (2013), kelemahan dari arang aktif adalah harga yang cukup mahal yang tidak sesuai dengan daya beli masyarakat, sehingga masyarakat menggunakan arang non aktif, salah satu bahan pembuat arang yang berasal dari arang tempurung kelapa yang relatif murah. Dalam penelitian ini arang yang digunakan adalah arang non aktif yang dibakar sendiri dengan suhu tinggi.

Tempurung kelapa dipilih karena karbon yang terbuat dari tempurung kelapa paling efektif dibandingkan dengan arang kayu, bentuk serbuk dari tempurung kelapa memiliki struktur yang lebih halus dibandingkan tempurung kelapa jenis granular, sehingga bentuk serbuk biasa digunakan pada fase gas karena strukturnya yang halus apabila digunakan pada fase cair maka akan menyebabkan warna adsorbat terganggu [7].

\section{Kesimpulan}

1. Nilai kadar BOD pada air limbah domestik dengan media lembaran plastik, media batu pecah dan media arang tempurung kelapa dalam penelitian ini memiliki perbedaan yaitu kadar BOD sebelum perlakuan sebesar 131,2 mg/l, sedangkan kadar BOD sesudah perlakuan dengan media lembaran plastik pada replikasi pertama sebesar 23,99 mg/l, replikasi kedua sebesar 14,99 mg/l, replikasi ketiga sebesar 20,99 mg/l. Kadar BOD sesudah perlakuan dengan media batu pecah pada replikasi pertama sebesar 23,24 mg/l, replikasi kedua sebesar 29,99 mg/l, replikasi ketiga sebesar 23,24 mg/l. Kadar BOD sesudah perlakuan dengan media arang tempurung kelapa pada replikasi pertama sebesar $30,74 \mathrm{mg} / \mathrm{l}$, replikasi kedua sebesar $15,74 \mathrm{mg} / \mathrm{l}$, replikasi ketiga sebesar 72,74mg/l.

2. Nilai kadar COD pada air limbah domestik dengan media lembaran plastik, media batu pecah dan media arang tempurung kelapa dalam penelitian ini memiliki perbedaan yaitu kadar COD sebelum perlakuan sebesar 410,1mg/l,

3. sedangkan kadar COD sesudah perlakuan dengan media lembaran plastik pada replikasi pertama sebesar 74,97 mg/l, replikasi kedua sebesar 46,84 mg/l, replikasi ketiga sebesar $65,59 \mathrm{mg} / \mathrm{l}$. Kadar COD sesudah perlakuan dengan media batu pecah pada replikasi pertama sebesar 72,63 mg/l, replikasi kedua sebesar 93,72 mg/l, replikasi ketiga sebesar 72,63 mg/l. Kadar COD sesudah perlakuan dengan media arang tempurung kelapa pada replikasi pertama sebesar 96,06 mg/l, replikasi kedua sebesar 49,19 mg/l, replikasi ketiga sebesar $127,3 \mathrm{mg} / \mathrm{l}$.

\section{Saran}

1. Bagi peneliti lain dapat menambahkan metode aerasi agar penurunan kadar BOD, COD dan PH lebih optimal. Selain itu juga dapat melakukan dengan cara aerobik dengan sistem kontinyu. Pada media sebaiknya melakukan percobaan dengan menggunakan arang aktif, hal tersebut untuk mendapatkan hasil penurunan yang lebih baik lagi dan juga dapat memperluas variabel penelitian misalnya TSS, DO amoniak.

2. Bagi masyarakat supaya bisalebih menjaga dan memperhatikan pembuangan air agar tidak mencemari selokan dan sumur.

\section{Referensi}

[1] Chandra, B, (2007). Pengantar Kesehatan Lingkungan. Cetakan Pertama. Jakarta : Penerbit Industri Kecil Tekstil Dengan Proses Biofilter Anaerob-Aerob Tercelub Mengggunakan Media Plastik Sarang Tawon. Jurnal Teknologi Lingkungan.

[2] Switarto, B dan Sugito. (2012). Aplikasi Biofilter Aerobik Untuk Menurunkan Kandungan Detergen Pada Air Limbah Laundry. Jurnal Teknik.

[3] Anita Nurfitriyani, dkk. (2012). Penentuan Efisiensi Penyisihan Kromium Heksavalen $\left(\mathrm{Cr}^{6+}\right)$ Dengan Adsorbsi Menggunakan Tempurung Kelapa Secara Kontinyu. Jurnal Online Institut Teknologi Nasional (Online). Vol 20 (10), 1-12. 
[4] Badan Litbang Pertanian. (2011). Arang Aktif Meningkatkan Kualitas Lingkungan. Tersedia:http://www.litbang.pertanian.go.id/download/one/196/file/Arang-Aktif Meningkatkan-K.pdf. (Diakses pada 11 Maret 2016).

[5] Idaman Said, Nusa dan Ruliasih. (2005). Tinjauan Aspek Teknis Pemilihan Media Biofilter Untuk Pengolahan Air Limbah. Jurnal Teknologi Lingkungan (Online). Vol 1 (3), 272-281.

[6] Idaman Said, Nusa dan Firly. (2005). Uji Performance Biofilter Anaerobik Unggun Tetap Menggunakan Media Biofilter Sarang Tawon Untuk Pengolahan Air Limbah Rumah Potong Ayam. Jurnal Teknologi Lingkungan (Online). Vol 1 (3), 289-303. (Diakses pada16 Maret 2016).

[7] Mujiarto, Iman. (2005). Sifat dan Karakteristik Material Plastik Dan Bahan Aditif. (Online) Vol 3 (2). Tersedia: https://mesinunimus.files.wordpress.com/ 2008/02/sifatkarakteristik-material-plastik.pdf. Diakses pada 11 Maret 2016.

[8] Mulia, R.M. (2005). Kesehatan Lingkungan, Yogyakarta. Graha Ilmu.

[9] Muslim. (2010). Kemampuan Genteng Plastik Bergelombang (Corrugate Plastic) Sebagai Biofilter Partikel Amoniak Dan Bahan Organik Di Media Budidaya Dan Limbah Cair Budidaya Ikan. Jurnal Manusia Dan Lingkungan (Online). Vol 17 (2), 6977.

[10] Notoatmodjo, Soekidjo. (2010). Metodologi Penelitian Kesehatan, Rineka Cipta. Jakarta.

[11] Rejeki, Sri, (2015). Sanitasi, Hygiene dan Kesehatan dan Keselamatan Kerja, Rekayasa Sains. Bandung.

[12] Reza Cordova, M. (2008). Kajian Air Limbah Domestik Di Perumnas Bantar Kemang Kota Bogor dan Pengaruhnya Pada Sungai Ciliwung, Skripsi, Institut Pertanian Bogor.

[13] Soedarto. (2013). Lingkungan dan Kesehatan, Sagung Seto.Jakarta.

[14] Yusriani, S.D, dkk. (2013). Efektifitas Teknik Biofiltrasi Dengan Media Bio-Ball Terhadap Penurunan Kadar Nitrogen Total. Jurnal Ilmiah Fakultas Teknik LIMIT’S.Vol $9(1), 45-53$. 